Open Access

\title{
Hypoxia promotes the migration and invasion of human hepatocarcinoma cells through the HIF-1a-IL-8-Akt axis
}

\author{
Maoyun Fei ${ }^{1}$, Jianming Guan ${ }^{2}$, Tao Xue ${ }^{3}$, Lianjin Qin ${ }^{1}$, Chengwu Tang ${ }^{4}$, Ge Cui $^{1}$, Yao Wang ${ }^{1}$, Hui Gong ${ }^{3}$
} and Wenming Feng ${ }^{4^{*}}$

\author{
* Correspondence: \\ wenmingfeng2018@163.com \\ ${ }^{4}$ Department of Hepatobiliary \\ Pancreatic Surgery, The First \\ People's Hospital of Huzhou, No.158 \\ Guangchanghou RoadZhejiang \\ Province 313000 Huzhou, People's \\ Republic of China \\ Full list of author information is \\ available at the end of the article
}

\begin{abstract}
Background: Hepatocellular carcinoma (HCC) is the fifth most common cancer and the third most common cause of cancer-related death worldwide. The 5-year survival rate remains low despite considerable research into treatments of HCC, including surgery, radiotherapy and chemotherapy. Many mechanisms within HCC still require investigation, including the influence of hypoxia, which has a crucial role in many cancers and is associated with metastasis. Hypoxia inducible factor-1a (HIF-1a) is known to regulate the expression of many chemokines, including interleukin-8 (IL-8), which is associated with tumor metastasis. Although many studies have reported that HIF-1a is associated with HCC migration and invasion, the underlying mechanisms remain unknown.
\end{abstract}

Methods: The expression level of HIF-1a was determined in HCC cells. The correlation of IL-8 and HIF-1a expressions was assessed via knockdown of HIF-1a. HCC cells were also used to assess the influence of HIF-1a on HCC cell migration and invasion. LY294002, an inhibitor of the Akt pathway, was used to confirm the associated signaling pathways.

Results: We observed a significant attenuation of cell migration and invasion after silencing of HIF-1a. Exogenously expressing IL-8 restored migration and invasion. Akt was found to be involved in this process.

Conclusion: Hypoxia promotes HCC cell migration and invasion through the HIF-1a-IL8-Akt axis.

Keywords: Hepatocarcinoma, Hypoxia, HIF-1a, IL-8, Akt pathway

\section{Background}

Hepatocellular carcinoma (HCC) is the fifth most common cancer and the third most common cause of cancer-related death worldwide [1]. Although advances have been made in diagnostic and treatment strategies, the 5-year survival rate remains low because of the high rates of metastasis [2,3]. Several pathogenic mechanisms and factors associated with HCC have been documented, but the molecular mechanisms of HCC migration and invasion still need investigation [4].

Previous studies showed that hypoxia promotes metastasis by inducing hypoxia inducible factor-1 (HIF-1) [5-7]. HIF-1 consists of two subunits: HIF-1ß: a constitutively expressed subunit; and HIF- $1 \alpha$, an activity-determining unit that regulates tumor metabolism, proliferation and metastasis [8-10]. Recent studies showed that HIF-1 $\alpha$ has a role in HCC cell

(c) The Author(s). 2018 Open Access This article is distributed under the terms of the Creative Commons Attribution 4.0 International License (http://creativecommons.org/licenses/by/4.0/), which permits unrestricted use, distribution, and reproduction in any medium, provided you give appropriate credit to the original author(s) and the source, provide a link to the Creative Commons license, and indicate if changes were made. The Creative Commons Public Domain Dedication waiver (http://creativecommons.org/ publicdomain/zero/1.0/) applies to the data made available in this article, unless otherwise stated. 
migration and invasion [11-13]. This concurs with our finding that HCC cell migration and invasion are sharply attenuated by knockdown of HIF-1 $\alpha$ under conditions of hypoxia. However, the underlying mechanisms remain largely unknown.

It is known that HIF- $1 \alpha$ can stimulate the expression of various cytokines and chemokines [14-17]. Interleukin-8 (IL-8) is a chemokine with tumorigenic properties. It is associated with tumor metastasis in several cancer types [18-20]. A previous study illustrated that cells can produce IL-8 in response to hypoxia [21]. IL-8 was also recently reportedto be co-expressed with HIF- $1 \alpha$ in HCC with this co-expression is associated with metastasis and poor prognosis in HCC [11].

In this study, we found that IL-8 is regulated by hypoxia induced-HIF-1 $\alpha$ and that it can restore HCC cell migration and invasion attenuated by knockdown of HIF-1 $\alpha$. This suggests a correlation between HIF- $1 \alpha$ and IL- 8 expression and a significant role for this correlation on HCC cell migration and invasion.

The Akt signaling pathway is one of the key mechanisms of tumor survival. It has the ability to promote metastasis [22]. A recent study demonstrated that IL-8 promotes the invasion of human osteosarcoma cells through the Akt signaling pathway [23]. Here, we observed that the addition of an Akt pathway inhibitor decreased HCC cell migration and invasion, while exogenous expression of HIF-1 $\alpha$ prevented this decrease. Our conclusion is that HIF-1 $\alpha$ promotes HCC cell migration and invasion through the IL-8-Akt axis.

\section{Materials and methods}

\section{Cell cultures}

The human HCC cell lines Hep3B andHuh7 and the normal liver cell line WRL68 were obtained from the Shanghai Institute of Biological Sciences of the Chinese Academy of Sciences. The cells were cultured in Dulbecco's modified Eagle's medium (DMEM) supplemented with 10\% fetal bovine serum (FBS;GIBCO-BRL) in a humidified atmosphere of $95 \%$ normal air and $5 \% \mathrm{CO}_{2}$ at $37{ }^{\circ} \mathrm{C}$. For the hypoxia experiments, the cells were incubated in a humidified HetoMulti-gas incubator with an atmosphere of $1 \% \mathrm{O}_{2}, 5 \% \mathrm{CO}_{2}$ and $94 \% \mathrm{~N}_{2}$.

\section{RNA isolation and quantitative RT-PCR}

Total RNA was extracted from the cells using the Trizol reagent (Invitrogen) according to the manufacturer's protocol. Reverse transcription was performed using a PrimeScript RT Reagent Kit (TaKaRa). For quantitative RT-PCR, cDNA was amplified using SYBR Premix Ex Taq (TaKaRa). Glyceraldehydes-3-phosphate dehydrogenase (GAPDH) was used as a control and the experiments were performed in triplicate. The primer sequences were:

HIF-1 $\alpha$ sense, 5'-GAACGTCGAAAAGAAAAGTCTC-3'

HIF- $1 \alpha$ antisense, 5'-CCTTATCAAGATGCGAACTCACA-3'

IL-8 sense, 5'-CAGCCTTCCTGATTTCTGC-3'

IL-8 antisense, 5' -GGGTGGAAAGGTTTGGAGTA-3'

GAPDH sense, 5'-TGACTTCAACAGCGACACCCA-3'

GAPDH antisense, 5'-CACCCTGTTGCTGTAGCCAAA-3' 


\section{Western blot analysis}

Total cell lysates were subjected to $10 \%$ SDS-PAGE and the proteins were transferred to nitrocellulose filter membranes, followed by blocking for $1 \mathrm{~h}$ in $5 \%$ non-fat dry milk. The membranes were incubated with primary antibodies at $4{ }^{\circ} \mathrm{C}$ overnight, and then with secondary antibodies at room temperature for $2 \mathrm{~h}$. GAPDH was used as a gel loading control.

\section{Cell migration and invasion assays}

For the migration assay, transwell chambers (Corning) with $8-\mu \mathrm{m}$ pore size polycarbonate filter inserts for 24-well plates were used according to the manufacturer's instructions. $1 \times 10^{5}$ ells were seeded onto the upper compartment in $200 \mu \mathrm{l}$ DMEM with $0.1 \%$ FBS followed by placement into wells containing $500 \mu \mathrm{l}$ complete medium in the lower chamber for $24 \mathrm{~h}$ at $37^{\circ} \mathrm{C}$. Then, the cells on the upper surface of membrane were removed and the cells attached to the lower surface of membrane were fixed and stained with Giemsa stain. The number of cells was counted under an inverted microscope.

Invasion was assayed using the same procedure as the migration assay, except that $70 \mu \mathrm{l}$ of $1 \mathrm{mg} / \mathrm{ml}$ Matrigel (BD Biosciences) was added to the upper face of the membrane. Assays were repeated three times.

\section{Small interfering RNA (siRNA) and transient transfection}

siRHIF- $1 \alpha$ was generated with the sequence 5'-GUGAUGAAAGAAUUACGAAUTT-3' (sense) and 5'-AUUCGGUAAUUCUUUCAUCACTT-3' (antisense), used to generate pSilencer3.1-HIF-1 $\alpha$ as previously described [11]. The scrambled sequences 5'-UUCU CCGAACGUGUCACGUdTdT-3' and 5'-ACGUGACACGUUCGGAGAAdTdT-3' were produced. siRNA transfection was performed using Lipofectamine 3000 (Invitrogen).

\section{Chromatin immunoprecipitation (ChIP) assay}

Anti-HIF-1 $\alpha$ antibody (R\&D Systems) was used to immunoprecipitate sonicated chromatins prepared from HCC cell lines. IgG was used as a control. Immunoprecipitated DNA was quantified for the IL-8 promoter segments using real-time PCR. The primer sequences were:

\section{Forward primer, 5'-CCCTCGAGCATACTCCGTATTTGATAAGGAAC-3'}

Reverse primer, 5'-GGCTCTTGTCCTAGAAGCTT-3'

\section{Statistical analysis}

All data are presented as means \pm SD (standard deviation). Differences between groups were tested for statistical significance using Student's $t$-test or $\chi^{2}$-test. $p<0.05$ was considered statistically significant.

\section{Results}

The high expression level of HIF-1a in HCC under conditions of hypoxia

Quantitative RT-PCR was performed to assess the expression level of HIF-1 $\alpha$ in the human HCC cell lines Hep3B and Huh7 and the control liver cell line WRL68 under conditions of hypoxia and normoxia. The mRNA level of HIF-1 $\alpha$ was significantly higher in both HCC cell lines than in WRL68 under hypoxia, while there were no statistical 
differences between the HIF- $1 \alpha$ expression levels for the three cell lines under normoxia (Fig. 1a). The results of the western blot assay concurred with this result (Fig. 1b). This suggests that hypoxia may promote HIF-1 $\alpha$ expression in HCC cell lines. The expression profiles of IL-8 in the HCC cell lines and normal liver cells also correlate with those of HIF-1 $\alpha$ (Fig. $1 \mathrm{~b}$ and c).

\section{HIF- $1 a$ is associated with migration and invasion of HCC through the regulation of IL-8 expression under conditions of hypoxia}

siHIF- $1 \alpha$ was introduced to silence HIF- $1 \alpha$, and was confirmed effective at the mRNA level (Fig. 1d, left panel) and protein level (Fig. 1e) in both HCC cell lines under hypoxia. In addition, compared with the control and scrambled groups, at both the mRNA level (Fig. 1d, right panel) and protein level (Fig. 1e), IL-8 was significantly downregulated by the silencing of HIF- $1 \alpha$ in both HCC cell lines, suggesting that IL- 8 expression may be regulated by HIF- $1 \alpha$. ChIP-qRT-PCR was performed using an anti-HIF- $1 \alpha$ antibody or an IgG control in both HCC cell lines under conditions of hypoxia. The results showed that HIF- $1 \alpha$ directly associated with the IL- 8 promoter region, confirming that IL- 8 was activated by HIF- $1 \alpha$ in HCC cells under hypoxia (Fig. 2a).

The roles of HIF-1 1ain HCC cell migration and invasion were assessed using the transwell assay. siHIF- $1 \alpha$ was transfected into Hep3B cells under hypoxia or normoxia. With conditions of hypoxia, the number of migrated and invaded cells sharply decreased when HIF- $1 \alpha$ was silenced ( 420 vs. 232 migrated cells per field and 524 vs. 276 invaded cells per field). This was not observed under normoxia (Fig. 2b and c, 207 vs. 149 migrated cells per field and 224 vs. 146 invaded cells per field). This implies the elimination of HIF-1 $\alpha$-attenuated HCC cell migration and invasion under hypoxia. Overexpression of IL-8 restored the migratory and invasive capacities of HCC cells transfected with siHIF-1 $\alpha$ (Fig. $2 \mathrm{~b}$ and c, from 149 to 188 migrated cells and from 276 to 457 invaded cells per field). Therefore, IL- 8 expression may be regulated by HIF- $1 \alpha$ and HIF- $1 \alpha$ may promote HCC cell migration and invasion by regulating IL- 8 expression under conditions of hypoxia.

\section{Exogenous HIF-1a restored the migration and invasion that was attenuated by Akt pathway inhibition}

A recent study demonstrated that IL-8 promotes the invasion of human osteosarcoma cells through the Akt signaling pathway. This pathway is associated with metastasis in many tumor types. We hypothesized that the effect of HIF-1 $\alpha$ on HCC cell migration and invasion could be associated with IL-8-induced Akt pathway activation. To confirm this hypothesis, we transfected siHIF-1 $\alpha$ into Hep3B cells under conditions of hypoxia or normoxia, and then determined the pAkt expression level. The results show that the expression level of IL-8 decreased after HIF- $1 \alpha$ silencing under hypoxia. In addition, the protein level of pAkt was simultaneously decreased (Fig. 2d), indicating that HIF- $1 \alpha$ may regulate IL- 8 and thereby promote Akt pathway activation.

To further investigate the role of the HIF-1 $\alpha-$ IL-8-Akt axis on HCC cell migration and invasion, the Akt inhibitor LY294002 was introduced. Hep3B cells were treated with $10 \mu \mathrm{M}$ LY294002 followed by a transwell assay to assess the number of migrated and invaded HCC cells under hypoxia. The results showed an obvious decrease in the 

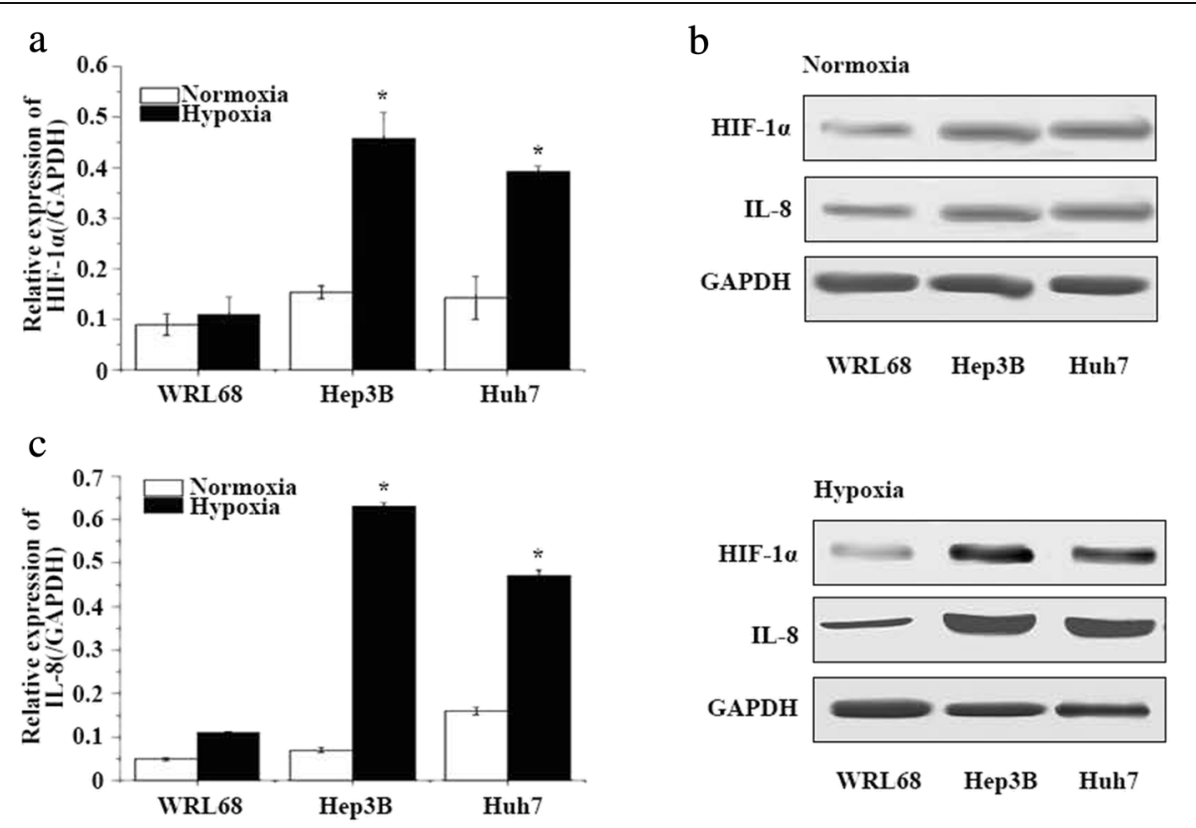

d
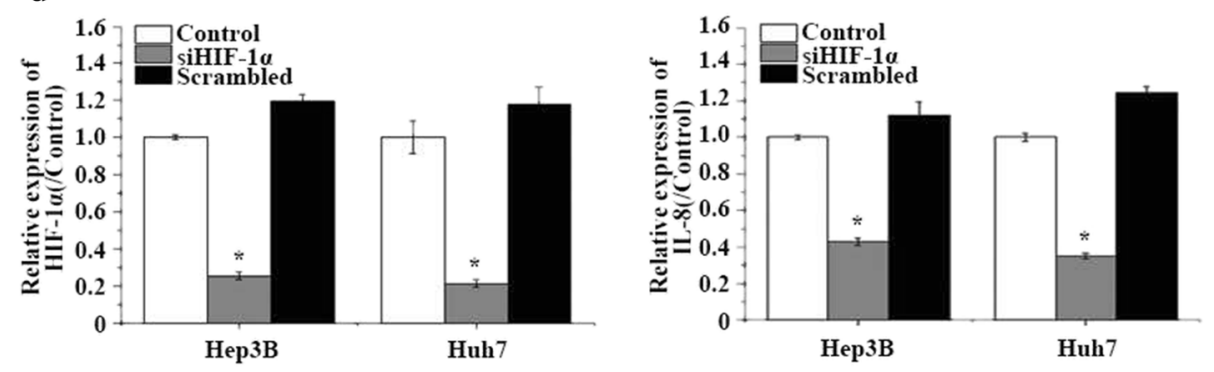

e
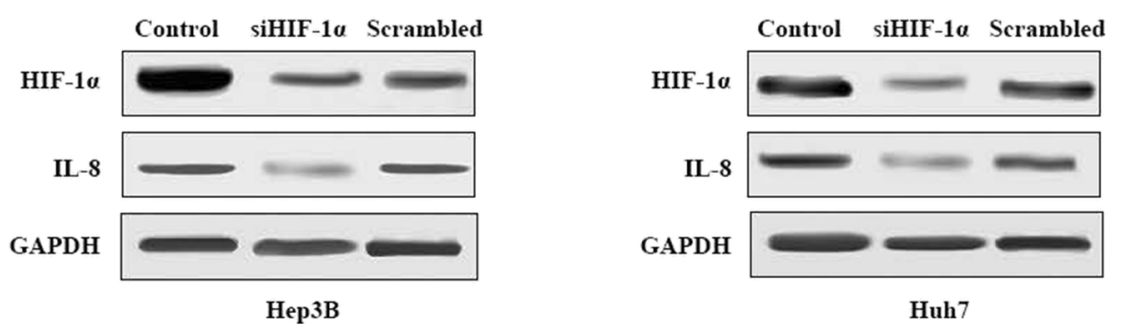

Fig. $1 \mathrm{HIF-1a}$ is associated with the migration and invasion of human hepatocarcinoma (HCC)cells by regulating IL-8 expression under conditions of hypoxia. a Relative HIF-1a mRNA levels in human HCC cell lines and the normal liver cell line WRL68. $n=3 ;{ }^{*} p<0.05$. $\mathbf{b}$ HIF-1 $a$ and IL-8 protein levelsin HCC cell lines and the normal liver cell line WRL68. GAPDH was used as the loading control. $\mathbf{c}$ Relative IL-8 mRNA levels in human HCC cell lines and the normal liver cell line WRL68. $n=3$; ${ }^{*} p<0.05$. $\mathbf{d}$ The efficiency of HIF-1a knockdown in HCC cell lines (left panel) and the effect on IL-8 expression (right panel) were evaluated using quantitative RT-PCR. e Western blot analysis of HIF-1a and IL-8 protein expression in HCC cell lines treated with siHIF-1a. GAPDH was used as a control. $n=3 ;{ }^{*} p<0.05$

relative migration and invasion of $\mathrm{HCC}$ cells after Akt pathway inhibition (Fig. 2e and f). However, exogenous expression of HIF-1 $1 \alpha$ significantly increased the number of migrating and invading HCC cells compared to the group without LY294002 treatment. Therefore, hypoxia may promote $\mathrm{HCC}$ cell migration and invasion through the HIF-1 $\alpha-$ IL-8-Akt axis. 


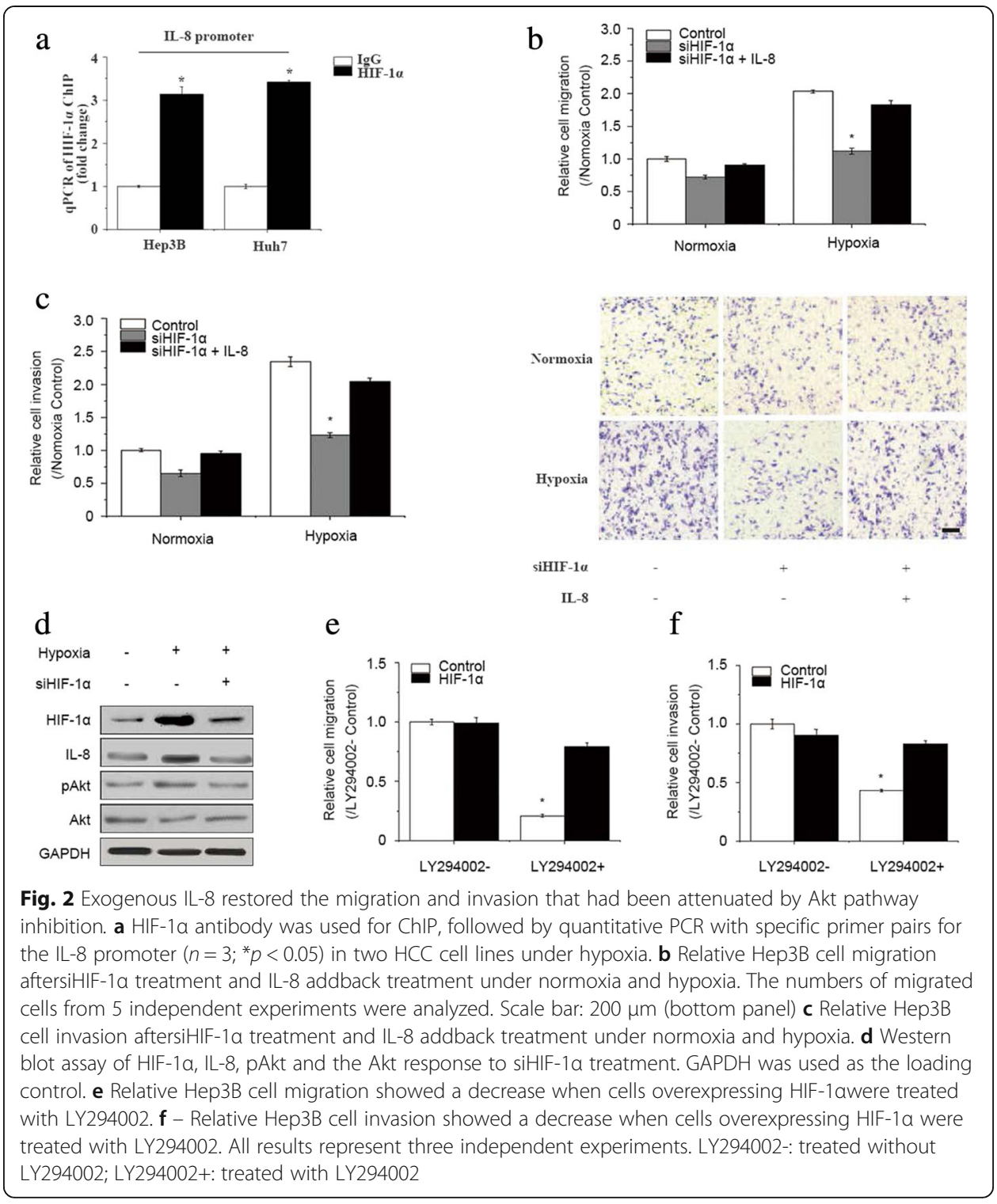

\section{Discussion}

Hypoxia plays an important role in many cancers and hypoxia-inducible factors are crucial mediators of the hypoxia response [14]. In cancer, intratumoral hypoxia promotes tumor aggressiveness, increasing metastasis and patient mortality. The activation of HIF-1 $\alpha$ is known to play a role in this [24]. Previous studies have reported that hypoxia promotes $\mathrm{HCC}$ invasion and progression and that overexpression or stabilization of HIF- $1 \alpha$ is involved [25, 26]. This is consistent with our results showing that HIF- $1 \alpha$ was highly expressed in HCC cells under conditions of hypoxia and that hypoxia-induced HIF- $1 \alpha$ promoted HCC cell migration and invasion.

HIF- $1 \alpha$ regulates the expression levels of various chemokines and their receptors to promote the proliferation and metastasis of many cancers [27-29]. IL-8, also known as CXCL8, is a chemokine with a role in metastatic and advanced cancers. It promotes tumor growth, metastasis and angiogenesis [21, 30]. A recent study proved that co-expression of IL-8and HIF-1 $\alpha$ is associated with metastasis and poor prognosis in 
hepatocellular carcinoma [11]. In this study, we found that the expression of IL-8 was regulated by HIF- $1 \alpha$ in HCC cells under hypoxia, and that overexpression of IL- 8 increased the number of migrated and invaded cells, even reversing the attenuation caused by HIF- $1 \alpha$ silencing. This suggests that IL- 8 is essential for HIF- $1 \alpha$-promoted HCC cell migration and invasion.

The Akt pathway is known to be involved in tumor metastasis [22], and a target of AKT, mTOR, is associated with promoting proliferation and differentiation, and inhibiting apoptosis [31]. A recent study showed that the Akt pathway is activated in HCC cells under hypoxia [11]. In this study, we observed that an Akt inhibitor, LY294002, attenuated HCC cell migration and invasion, but exogenous HIF-1 1 reversed these effects. Additionally, silencing of HIF- $1 \alpha$ simultaneously downregulates the expression levels of IL-8 and Akt, suggesting a correlation betweenIL-8, HIF-1 $\alpha$ and Akt. However, how the Akt pathway further promotes HCC cell migration and invasion and the mechanism of how HIF-1 $\alpha$ regulates IL- 8 were not covered in this study. Further research can focus on these questions.

\title{
Conclusion
}

Hypoxia activates HIF- $1 \alpha$ in HCC cells to regulate IL-8 expression, and thereby promotes HCC cell migration and invasion through the Akt pathway.

Abbreviations

CXCL8: C-X-C motif ligand 8; HCC: Hepatocellular carcinoma; HIF-1a: Hypoxia inducible factor-1a; IL-8: Interleukin-8

\section{Funding}

This research was supported by the Medical Scientific Research Project of Zhejiang Province, jointly supported by the Province and the Ministry (grant number 2015PYA011); the Public Welfare Technical Applied Research Project of Zhejiang Province (grant number 2014C33135); the Natural Science Foundation of Zhejiang Province (grant number LQ16C080001); the Medical Scientific Research Project of Zhejiang Province (grant number 2015KYB372); and the Public Welfare Technical Applied Research Project of Huzhou City (key program; grant number 2015GZ14).

\section{Authors' contributions}

MF created the study concept and wrote and edited the manuscript. TX and JG contributed to the writing and prepared the figures and references. All the authors have read and approved the final manuscript.

\section{Ethics approval and consent to participate}

Not applicable.

\section{Consent for publication}

Not applicable.

Competing interests

All the authors declare that they have no competing interests.

\section{Publisher's Note}

Springer Nature remains neutral with regard to jurisdictional claims in published maps and institutional affiliations.

\begin{abstract}
Author details
'Department of General Surgery, The First People's Hospital of Huzhou, No.158 Guangchanghou RoadZhejiang Province 313000 Huzhou, People's Republic of China. ${ }^{2}$ Department of Ultrasound, The First People's Hospital of Huzhou, No.158 Guangchanghou RoadZhejiang Province 313000 Huzhou, People's Republic of China. ${ }^{3}$ Central Laboratory, The First People's Hospital of Huzhou, No.158 Guangchanghou RoadZhejiang Province 313000 Huzhou, People's Republic of China. ${ }^{4}$ Department of Hepatobiliary Pancreatic Surgery, The First People's Hospital of Huzhou, No.158 Guangchanghou RoadZhejiang Province 313000 Huzhou, People's Republic of China.
\end{abstract}

Received: 17 March 2018 Accepted: 13 July 2018

Published online: 20 September 2018

\section{References}

1. Tang Z-Y, Ye S-L, Liu Y-K, Qin L-X, Sun H-C, Ye Q-H, et al. A decade's studies on metastasis of hepatocellular carcinoma.Journal of Cancer research and. Clin Oncol. 2004:130(4):187-96.

2. Forner A, Llovet JM, Bruix J. Hepatocellular carcinoma. Lancet. 2012;379(9822):1245-55. 
3. Portolani N, Coniglio A, Ghidoni S, Giovanelli M, Benetti A, Tiberio GAM, et al. Early and late recurrence after liver resection for hepatocellular carcinoma: prognostic and therapeutic implications. Ann Surg. 2006;243(2):229-35.

4. Aravalli RN, Steer CJ, Cressman ENK. Molecular mechanisms of hepatocellular carcinoma. Hepatology. 2008;48(6):2047-63.

5. Gordan JD, Simon MC. Hypoxia inducible factors: central regulators of the tumor phenotype. Curr Opin Genet Dev. 2007;17(1):71-7.

6. Semenza GL. Targeting HIF-1 for cancer therapy. Nat Rev Cancer. 2003;3(10):721-32.

7. Marc AV, Eelke HG, Arjan JG, Elsken van der W, Paul JD. Hypoxic regulation of metastasis via hypoxia-inducible factors. Curr Mol Med. 2008;8(1):60-7.

8. Semenza GL, Wang GL. A nuclear factor induced by hypoxia via de novo protein synthesis binds to the human erythropoietin gene enhancer at a site required for transcriptional activation. Mol Cell Biol. 1992;12(12):5447-54.

9. Denko NC. Hypoxia, HIF1 and glucose metabolism in the solid tumour. Nat Rev Cancer. 2008;8(9):705-13.

10. Li Y, Ye D. Cancer therapy by targeting hypoxia-inducible Factor-1. Curr Cancer Drug Targets. 2010;10(7):782-96.

11. Li X-P, Yang X-Y, Biskup E, Zhou J, Li H-L, Wu Y-F, et al. Co-expression of CXCL8 and HIF-1a is associated with metastasis and poor prognosis in hepatocellular carcinoma. Oncotarget. 2015;6(26):22880-9.

12. Tian H, Huang P, Zhao Z, Tang W, Xia J. HIF-1alpha plays a role in the chemotactic migration of hepatocarcinoma cells through the modulation of CXCL6 expression. Cell Physiol Biochem. 2014;34(5):1536-46.

13. Ye M, Fang Z, Gu H, Song R, Ye J, Li H, et al. Histone deacetylase 5 promotes the migration and invasion of hepatocellular carcinoma via increasing the transcription of hypoxia-inducible factor-1alpha under hypoxia condition. Tumour Biol. 2017;39(6):1010428317705034

14. Yang M-H, Wu K-J. TWIST activation by hypoxia inducible factor-1 (HIF-1): implications in metastasis and development. Cell Cycle. 2008;7(14):2090-6.

15. Mojsilovic-Petrovic J, Callaghan D, Cui H, Dean C, Stanimirovic DB, Zhang W. Hypoxia-inducible factor-1 (HIF-1) is involved in the regulation of hypoxia-stimulated expression of monocyte chemoattractant protein-1 (MCP-1/ CCL2) and MCP-5 (CCl12) in astrocytes. J Neuroinflammation. 2007:4:12.

16. Baay-Guzman GJ, Bebenek IG, Zeidler M, Hernandez-Pando R, Vega MI, Garcia-Zepeda EA, et al. HIF-1 expression is associated with CCL2 chemokine expression in airway inflammatory cells: implications in allergic airway inflammation. Respir Res. 2012;13(1):60

17. Koizumi K, Hojo S, Akashi T, Yasumoto K, Saiki I. Chemokine receptors in cancer metastasis and cancer cell-derived chemokines in host immune response. Cancer Sci. 2007;98(11):1652-8.

18. Bai Z, Tai Y, Li W, Zhen C, Gu W, Jian Z, et al. Gankyrin activates IL-8 to promote hepatic metastasis of colorectal Cancer. Cancer Res. 2013;73(14):4548.

19. Lin S-C, Hsiao K-Y, Chang N, Hou P-C, Tsai S-J. Loss of dual-specificity phosphatase-2 promotes angiogenesis and metastasis via up-regulation of interleukin-8 in colon cancer. J Pathol. 2017;241(5):638-48.

20. Shoshan E, Braeuer RR, Kamiya T, Mobley AK, Huang L, Vasquez ME, et al. NFAT1 directly regulates IL8 and MMP3 to promote melanoma tumor growth and metastasis. Cancer Res. 2016;76(11):3145.

21. Brat DJ, Bellail AC, Van Meir EG. The role of interleukin-8 and its receptors in gliomagenesis and tumoral angiogenesis. Neuro-Oncology. 2005;7(2):122-33.

22. Sheng S, Qiao M, Pardee AB. Metastasis and AKT activation. J Cell Physiol. 2009;218(3):451-4.

23. Jiang H, Wang X, Miao W, Wang B, Qiu Y. CXCL8 promotes the invasion of human osteosarcoma cells by regulation of PI3K/Akt signaling pathway. APMIS. 2017;125(9):773-80.

24. Maxwell PH. The HIF pathway in cancer. Semin Cell Dev Biol. 2005;16(4):523-30.

25. Zhang L, Huang G, Li X, Zhang Y, Jiang Y, Shen J, et al. Hypoxia induces epithelial-mesenchymal transition via activation of SNAI1 by hypoxia-inducible factor -1a in hepatocellular carcinoma. BMC Cancer. 2013;13:108.

26. Liu Y, Zhang J-B, Qin Y, Wang W, Wei L, Teng Y, et al. PROX1 promotes hepatocellular carcinoma metastasis by way of up-regulating hypoxia-inducible factor 1a expression and protein stability. Hepatology. 2013;58(2):692-705.

27. Lee YS, Choi I, Ning Y, Kim NY, Khatchadourian V, Yang D, et al. Interleukin-8 and its receptor CXCR2 in the tumour microenvironment promote colon cancer growth, progression and metastasis. Br J Cancer. 2012;106(11):1833-41.

28. McClelland MR, Carskadon SL, Zhao L, White ES, Beer DG, Orringer MB, et al. Diversity of the angiogenic phenotype in non-small cell lung cancer. Am J Respir Cell Mol Biol. 2007;36(3):343-50.

29. Doll D, Keller L, Maak M, Boulesteix A-L, Siewert JR, Holzmann B, et al. Differential expression of the chemokines GRO-2, GRO-3, and interleukin-8 in colon cancer and their impact on metastatic disease and survival. Int J Color Dis. 2010;25(5):573-81.

30. Yoshimura T, Matsushima K, Oppenheim JJ, Leonard EJ. Pillars article: neutrophil chemotactic factor produced by lipopolysaccharide (LPS)-stimulated human blood mononuclear leukocytes: partial characterization and separation from interleukin 1 (IL 1). J Immunol. 2005;175(9):5569.

31. Weichhart T. Mammalian target of rapamycin: a signaling kinase for every aspect of cellular life in mTOR: methods and protocols. Totowa: Humana Press; 2012. p. 1-14.

Ready to submit your research? Choose BMC and benefit from:

- fast, convenient online submission

- thorough peer review by experienced researchers in your field

- rapid publication on acceptance

- support for research data, including large and complex data types

- gold Open Access which fosters wider collaboration and increased citations

- maximum visibility for your research: over 100M website views per year

At $B M C$, research is always in progress.

Learn more biomedcentral.com/submissions 